\title{
Baby Walker Use and Child Development
}

\author{
Melike METEE ${ }^{1,2}$, Gonca KESKINDEMIRCi ${ }^{*}$ and Gülbin GÖKÇAY $Y^{2,3}$ \\ ${ }^{1}$ Institude of Child Health, Istanbul University, Turkey \\ ${ }^{2}$ Department of Pediatrics and Child Health, School of Medicine, Istanbul University, Turkey \\ ${ }^{3}$ Department of Social Pediatrics, Institute of Child Health, Istanbul University, Turkey
}

*Corresponding author: Gonca Keskindemirci, Department of Pediatrics and Child Health, School of Medicine, Istanbul University, Istanbul Tip Fakültesi Çocuk Sağliği ve Hastaliklari Anabilim Dali Çapa Istanbul, Turkey

\begin{abstract}
Objective: To evaluate the effect of baby walker (BW) use on child development.

Methods: The study was conducted in İstanbul University İstanbul Medical Faculty Social Pediatric Outpatient Clinic. Children aged 18-30 months who used BW for 30 minutes or more a day for at least 1 month constituted the user group $(n=100)$ and those who never used a BW were in the control group $(n=100)$. Information was obtained through the personal health record of the unit and by a face-to-face questionnaire applied to the families during their visits to the unit. The Ankara Development Screening Inventory (ADSI) was used to assess language-cognitive, motor and mental development. Sitting without support and independent walking age and four measures (history and physical, neurological and orthopedic examinations) of gait disorders were evaluated in relation to child development.
\end{abstract}

Results: There was no developmental problem in any of the children, but there was a statistically significant difference in terms of an atypical gait pattern between the two groups Atypical gait pattern and especially toe-walking were more frequent in children who used BW. The accident rate in BW users was also significantly higher than those who did not use BW. The most common reasons for BW use were keeping the child occupied and improving his/her development.

Conclusion: The use of BW should be considered while evaluating toe-walking in children. To convince families in avoiding use of BW, they need to be informed that it has no positive influence on motor development but carries a risk for accidents and toe walking. This information should be part of the parent education offered in Well Child Clinics.

\section{Keywords}

Baby Walker, Development, Child

\begin{abstract}
Abbreviations
BW: Baby Walker; ADSI: Ankara Development Screening Inventory; SCAST: Social-Communication Area Developmental Screening Test; M-CHAT: Modified Checklist for Autism in Toddlers; DDST: Denver II Developmental Screening Test; AIMS: Alberta Infant Motor Development Scale
\end{abstract}

\section{Introduction}

The baby walker (BW) has been used since the early 1660 s to mobilize babies before the independent gait is acquired [1]. BW is still widely used around the world [2-8]. On the other hand, BW use is not recommended by some pediatric associations and its safety standards have been revised in the USA [9-11]. Many families still continue to use BW walkers to keep the child occupied or to accelerate his/her development $[8,12]$. Studies about the effects of BW use on child development report conflicting results, some reporting adverse effects while others reporting no such effect $[5,13,14]$. On the other hand it is was reported that falling down from the baby walker was common the most form of the accident related to baby walker [15]. During our well child visits we observed that BW use (Figure 1) was common among toe-walkers, and a small-multicentered crosssectional study confirmed this observation [8].

As Badihian, et al. pointed out, there are a few studies evaluating the relationship between BW use and child development [16]. Siegel and Burton evaluated 109 children aged 6-15 months with the Bayley III Developmental Scale. Motor and mental scores of infants using BW were found to be low and this difference was statistically significant. There were no 


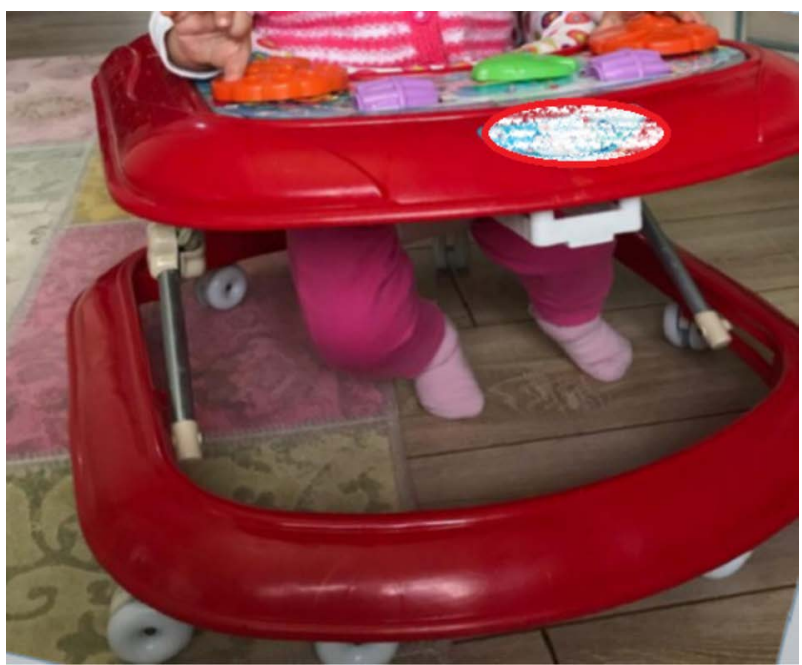

Figure 1: Baby walker.

variables in the study such as parental socio-economic characteristics or duration of daily BW use [13]. Thein, et al. evaluated 185 babies aged 7-10 months with Denver II Developmental Screening Test (DDST), and reported that DDST results of all children who did not use BW were "normal" while $7.2 \%$ of BW users had "abnormal" and 3.6\% "suspect" results. The majority of the infants with "abnormal" and "suspect" results were found to be retarded in gross motor skills. The number of infants who did not use BW was very low $(n=18)$, and the test results may have also been affected by the socioeconomic differences of the study sample [5]. Chagas, et al. evaluated 12-months-old infants with the Alberta Infant Motor Development Scale (AIMS) until they were 18-months-old or until they learnt to walk independently. They found that the use of a BW did not influence the independent walking age [14]. However, the study sample was limited to 26 child-parent pairs. Also, AIMS scores and results of the statistical analysis were not reported in the study findings.

The aim of this present study was to investigate the influence of BW use on the development of 18-30 month-old children

\section{Materials and Methods}

The universe of this semi-prospective case-control study was 18-30 month-old 336 children who presented consecutively to the Istanbul University School of Medicine Department of Social Pediatrics Well Child Unit between July 2015 and December 2015, on the first 4 days of the week, at which time the primary investigator (MM) was available.

Children who used a BW for 30 minutes or more a day for at least 1 month constituted the user group and those who never used a walker were in the control group. A pilot study on 20 children (10 BW users and 10 non users) was carried out to determine the sample size of the study. According to the power analysis allowing $5 \%$ for type 1 error, $10 \%$ for type 2 error, and two items difference between groups, a minimum of 84 children were found to be required for each group. Accordingly, allowing a $20 \%$ loss during the follow-up, 100 , children were planned to be selected for each group. Allocation of the children was stopped when the number was reached in each group. None of caregivers refused to participate in the study. Children who were born before $37^{\text {th }}$ gestation week, those who had a chronic/ congenital/neurological diseases, those who had a history of hospitalization, those who have been using BW for less than a month or less than 30 minutes a day ( $n=136$ ) were not included in the study.

In the Unit where the study was conducted, children are followed from birth up to the age of ten years for well-child controls. These controls are carried out at monthly intervals during the first 6 months of life, every 3 months until 18 months of age, and subsequently continued every 6 months. Each child has a medical record in the Unit and relevant data including physical examination findings, anthropometric measurements, and nutritional history were available in these records. Each child had undergone the social-communication area developmental screening test (SCAST) at 9 and 15 months of age and M-CHAT (Modified Checklist for Autism in Toddlers) at 18 and 24 months of age routinely. SCAST was developed in the Unit and the validity of M-CHAT was also evaluated $[17,18]$. All families were informed that they should avoid using BW for their children, in case they asked a question about the use of BW during their well-child visits.

The parents were asked to provide information on the sociodemographic characteristics of the families, medical history of the children, reasons for BW use, history of accidents by a face to face questionnaire. Information about the gross motor development and gait pattern of the child was also obtained by the questionnaire. All children were examined while sitting, lying prone and running both toward and from the pediatrician. This was accomplished at the beginning of the visit. Children who mainly walked on the toes or the ball of the foot were defined as toe-walkers. A thorough neurologic and musculoskeletal examination was carried out to rule out any underlying condition. All toewalkers were followed-up for at least fifteen months.

Ankara Developmental Screening Inventory (ADSI), which evaluate general development, language and cogntion, fine motor, gross motor skillsand socialskills and self care, was applied to all children in the study for evaluation of their neuro-developmental status. The results of the ADSI were classified as "Normal" and "20\% or more lower than the age level" [19].

Written consent was obtained from the parents. The study was approved by the Ethical Committee of Istanbul University School of Medicine. Data were analysed using SPSS (Statistical Package for the Social Sciences, Chicago, IL, USA) 21.0. Chi-square test, student t-test, 
Kruskal Wallis test and correlation analysis were used for statistical evaluation. The results were evaluated with a $95 \%$ confidence interval, and $p<0.05$ was defined as statistically significant.

\section{Results}

Questionnaires were mostly answered by the mothers both in the BW user and the control groups. The two most common reasons for using the BW were to keep the baby occupied (45\%) and to enhance the neurodevelopment of the baby (38\%). The other reasons were recommendations of neighbours and relatives $(6 \%)$, to keep the child away from the floor
(3\%), not feeling cold on the floor for baby, health worker recommendations (2\%). No reasons were given by $6 \%$ of the parents.

In the BW user group, $76 \%$ of caregivers were mothers and this figure was significantly higher than that of the control group. In the BW user group, the educational levels of the parents were lower and the number of unemployed (housewives) mothers was higher than those of the children in the control group. The number of young parents was high in the BW group. All these differences were statistically significant. BW use in the other sibling was also significantly high in

Table 1: Characteristics of the groups in the study.

\begin{tabular}{|c|c|c|c|}
\hline & BW users & Controls & $\mathbf{p}$ \\
\hline & $(n=100)$ & $(n=100)$ & \\
\hline \multicolumn{4}{|l|}{ Survey answered by } \\
\hline Mother & 96 & 91 & 0.152 \\
\hline Others (father, sister, brother, grandmother, nursemaid) & 4 & 9 & \\
\hline \multicolumn{4}{|l|}{ Home care provider } \\
\hline Mother & 76 & 59 & 0.01 \\
\hline Others (father, nursemaid, sister, aunt, grandmother) & 24 & 41 & \\
\hline \multicolumn{4}{|l|}{ Maternal educational level } \\
\hline Literate & 1 & 3 & 0.011 \\
\hline$\leq 5$ years schooling & 24 & 14 & \\
\hline $6-11$ years & 46 & 31 & \\
\hline$\geq 12$ years & 29 & 52 & \\
\hline \multicolumn{4}{|l|}{ Employment status of the mother } \\
\hline Not working (housewife) & 76 & 59 & 0.035 \\
\hline Health worker & 8 & 12 & \\
\hline White collar worker & 16 & 29 & \\
\hline \multicolumn{4}{|l|}{ Paternal educational level } \\
\hline Literate & 0 & 1 & 0.033 \\
\hline$\leq 5$ years schooling & 20 & 12 & \\
\hline $6-11$ years & 48 & 39 & \\
\hline$\geq 12$ years & 32 & 48 & \\
\hline Employment status of the father & & & 0.411 \\
\hline Unemployed & 0 & 1 & \\
\hline Health sector & 5 & 8 & \\
\hline White collar worker & 95 & 91 & \\
\hline Maternal age (mean \pm SD) & $31.7 \pm 5.9$ & $34.3 \pm 5.1$ & $<0.05$ \\
\hline Paternal age (mean \pm SD) & $35.7 \pm 6.2$ & $37.5 \pm 5.5$ & $<0.05$ \\
\hline BW use in siblings & & & $<0.000$ \\
\hline Yes & 46 & 19 & \\
\hline No & 6 & 22 & \\
\hline No sibling & 48 & 58 & \\
\hline Gender (Female) & $55 \%$ & $44 \%$ & 0.120 \\
\hline Age (months) & $23.5 \pm 4.8$ & $23.5 \pm 4.4$ & 0.976 \\
\hline Exclusive breastfeeding duration (moths) & $4.4 \pm 2.4$ & $4.7 \pm 2.3$ & 0.583 \\
\hline Total breastfeeding duration (months) & $16.0 \pm 8.0$ & $17.6 \pm 6.9$ & 0.224 \\
\hline BW related accident & $24 \%$ & $0 \%$ & \\
\hline
\end{tabular}


the BW user group. The age and gender distributions of the children were similar in the two groups. There was no statistically significant difference between the groups in terms of mean age (BW group: $23.5 \pm 4.8$ months, control group: $23.5 \pm 4.4$ months), exclusive breastfeeding duration (BW group $4.4 \pm 2.4$ months, control group: $4.7 \pm 2.3$ months), total breastfeeding duration (BW group $16.0 \pm 8.0$ months, control group: $17.6 \pm 6.9$ months), kindergarden attendance, anthropometric measurements, and body mass index score (Table 1).

The age of onset of use of the BW was $7.4 \pm 1.6$ (Table 2). The age of independent walking was $12.3 \pm$ 1.6 months in children who started using BW in the first 7 months and $12.7 \pm 1.4$ months in children who started using at 8 months or later. There was a statistically significant positive correlation $(r=0.238, p=0.017)$ between the time to start using the BW (month) and the independent walking age. Walking independently was achieved at early ages in children who started to use the BW early.

In the BW user group, $24 \%$ of the children were

Table 2: Information related to baby walker use $(n=100)$.

\begin{tabular}{|l|l|}
\hline $\begin{array}{l}\text { Age at starting to use BW } \\
\text { (months) } \\
\text { (mean } \pm \text { SD) }\end{array}$ & $7.4 \pm 1.6$ \\
\hline $\begin{array}{l}\text { Duration of use (months) } \\
\text { (mean } \pm \text { SD) }\end{array}$ & $2.7 \pm 1.5$ (min: 1 max: 10) \\
\hline Daily walker use (minutes) & $22 \%$ \\
\hline $30-59$ & $44 \%$ \\
\hline $60-119$ & $12 \%$ \\
\hline $120-179$ & $13 \%$ \\
\hline $180-239$ & $9 \%$ \\
\hline$\geq 240$ & \\
\hline
\end{tabular}

reported to have had an accident related to BW (Table 1 ). The majority $(91.7 \%)$ of these accidents was overturning of BW and $8.3 \%$ of the accident was falling down stairs with BW. There was no child who had undergone an accident in the control group. The information related to baby walker use was Sitting without support (BW group: $6.7 \pm 0.9$ months, controls: $6.7 \pm 0.8$ months) and independent walking age (BW group: $12.5 \pm 0.5$ months, controls: $12.6 \pm 1.7$ months) were similar in two groups Of all children in the two groups, 60 had an atypical gait patterns. Prevalence of atypical gait was significantly high among BW users (Table 3). Of 200 children in the study, 32 were toe-walkers. Toe-walking was high in the BW user group and this difference was statistically significant. Toe-walking was bilateral in all children. No underlying condition was found in children with toewalking. As all parents in the BW user group, the parent of each toe walker was informed about stopping using BW if the child was in the user group. Nine months after the the beginning of the study, the parents of 32 children were contacted by phone to collect information about toe-walking status. Four children from BW user group and one from the control were reported to continue toe-walking. Six months later, the families were called again and it was learned that all children had stopped toe-walking.

There was no statistically significant difference between the two groups in terms of ADSI results (Table 4). Percentages of the children with normal values for general development, language and cognitive development, fine motor skills, gross motor skills, socila skills and self care were similar in two groups. Of all children in the study $76.5 \%(n=153)$ had SCAST results in their records. Test results were normal for $94.4 \%$ of the BW users and for $93.9 \%$ of the control group. This difference was not statistically significant ( $p=0.903)$. Of all children $88.5 \%$ had M-CHAT. The results of M-CHAT

Table 3: Child development outcomes among BW users and controls.

\begin{tabular}{|l|l|l|l|l|}
\hline & BW users (n= 100) & Controls (n= 100) & p & (95\% Cl) \\
\hline Sitting without support (months) & $6.7 \pm 0.9$ & $6.7 \pm 0.8$ & 0.737 & $(6.61-6.87)$ \\
\hline Independent walking age (months) & $12.5 \pm 0.5$ & $12.6 \pm 1.7$ & 0.484 & $(12.36-12.83)$ \\
\hline Atypical gait & & & 0.001 \\
\hline Yes & 41 & 19 & \\
\hline No & 59 & $81.62-1.97)$ \\
\hline Toe-walking & & 5 & 0.001 \\
\hline Yes & 27 & 95 & $(1.78-1.89)$ \\
\hline No & 73 & & 0.637 \\
\hline Stepping inward & & 11 & $(1.85-1.95)$ \\
\hline Yes & 9 & 89 & \\
\hline No & 91 & & 0.470 \\
\hline Other gait disorder (stepping outward, etc.) & & 3 & $(1.93-1.98)$ \\
\hline Yes & 5 & 97 & \\
\hline No & 95 & & \\
\hline
\end{tabular}


Table 4: Ankara Developmental Screening Inventory results in the two groups.

\begin{tabular}{|c|c|c|c|c|}
\hline & BW users \% & Controls \% & $\mathbf{p}$ & $(95 \% \mathrm{Cl})$ \\
\hline General development & & & & $(1.10-1.22)$ \\
\hline Normal & 87 & 86 & 0.0836 & \\
\hline $20 \%$ and lower & 13 & 14 & & \\
\hline Language and cognitive & & & & $(1.13-1.26)$ \\
\hline Normal & 84 & 85 & 0.0845 & \\
\hline $20 \%$ and lower & 16 & 15 & & \\
\hline Fine motor skills & & & & $(1.31-1.47)$ \\
\hline Normal & 64 & 65 & 0.883 & \\
\hline $20 \%$ and lower & 36 & 35 & & \\
\hline Gross motor skills & & & & $(1.00-1.07)$ \\
\hline Normal & 96 & 98 & 0.407 & \\
\hline $20 \%$ and lower & 4 & 2 & & \\
\hline Social skills and self care & & & & $(1.08-1.19)$ \\
\hline Normal & 87 & 89 & 0.663 & \\
\hline $20 \%$ and lower & 13 & 11 & & \\
\hline \multicolumn{5}{|l|}{ Total } \\
\hline 35 and lower & 5 & 6 & 0.924 & \\
\hline $36-39$ & 8 & 7 & & \\
\hline 39 and above & 87 & 87 & & \\
\hline
\end{tabular}

were similar in the two groups. The proportion of normal results was $98.8 \%$ in the BW user group and 100 $\%$ in the control. M-CHAT results of all children with toewalking were normal.

\section{Discussion}

According to our findings, housewives, young mothers, and less educated parents were more prone to use babywalkers. The two most common reasons for using the BW were to keep the baby occupied and to enhance his/her neurodevelopment. We did not detect any positive effect of using BW on child development. On the other hand, the prevalence of toe-walking and accidents were higher among BW users.

Some studies report no significant difference between the use and non-use of BW and age of unsupported sitting and age of independent walking, taken as markers of gross motor development $[4,8,14]$. Burrows and Griffiths found in their mini review that the use of BW may delay the start of independent walking [20]. In our study, infants who started to use BW at an early age also acquired independent walking ability earlier. It may be assumed that these babies were very active, so families started to use BW at an earlier age. The fact that the findings are different in the reported studies may be due to the small sample sizeand the differences in the definition of walker use.

The development and validation of the SCAST were carried out the same unit where our study was carried out [17]. With the ADSI and SCAST development in communication, fine and gross motor development, social skills were evaluated. In our study, we found no statistically significant difference between the users and non-users of BW in both tests. The paradox between our research results and some of the literature findings may be due to the universe of the research, to methodology, to use of different developmental tests, and to definition of BW use.

Toe-walking is a quite common reason for parental concern reported at a well-child visit. It is considered idiopathic when the children walk on their toes instead of walking with a typical gait. Idiopathic toe-walking is a diagnosis of exclusion, where other conditions such as cerebral palsy and some neurological conditions causing an equinus gait have been ruled out. This situation sometimes leads to further investigations for differential diagnosis. According to our findings, gait disorders and especially toe-walking were high among BW users versus the non-users and this difference was statistically significant. This may be due to efforts to promote walking in children who were not yet developmentally ready for walking. Since theresults of developmental tests (M-CHAT, SCAST and ADSI) were normal in BW users and non-users, toe walking might be solely due to the BW use. Therefore our results led us to suggest that the use of BW should be considered in assessing gait disorders, especially toe-walking in children. Multicentered prospective studies are also needed on this issue. In the literature, to our knowledge, there is only one study reporting the relationship between gait disturbance and BW use [8]. In this multi-centered cross-sectional study, it was found that toe-walking was significantly high in the BW group. BW use was not included in the reviews on toe-walking $[21,22]$. 
The use of BWwas shown to be a risk factor for accidents [9-12]. Studies on infant walker related injuries were usually based on national electronic injury survaillance system data A high point of our study was accidents presented by the toddlers who used walker. In our study $24 \%$ of BW users had BW related accidents, the majority was overturning. This finding also indicates the need to effectively inform parents about the risks of BW use.

Our study had some limitations. It was conducted only in one well-child unit where the majority of the families were from middle-high socioeconomic class and partially informed about the use of walkers. This may have led incomplete reporting of BW use in our study and indicates that the findings of our study cannot be generalized to the community. The univariate nature of the study was another limitation. There might be a number of confounding variables with significant differences between the BW user and controls that could disappear in a multivariate analysis. In spite of its limitations, our study offered important findings in a relatively large group of toddlers. These were toewalking and high accident rates among BW users.

\section{Conclusion}

Despite its disadvantages, BW's were used by many families. BW use has no positive influence on motor development but may create risks for accidents and toe-walking. These facts should be carefully explained to parents to convince them in avoiding use of BW.

\section{Acknowledgements}

The work was supported in part by the Child Health Association. The authors declared that they had no interest which could be perceived as a conflict or bias. The authors extended their thanks to the families and the children in the study.

\section{Authors Contribution}

Melike Mete: Design of study, selection of the cases, writing of the article; Gonca Keskindemirci: Statistical analysis, writing of the article, submission to the journal; Gülbin Gökçay: Design of study, writing of the article.

\section{References}

1. Coats TJ, Allen M (1991) Baby walker related injuries - a continuing problem. Arch Emerg Med 8: 52-55.

2. Kendrick D, Marsh P (1998) Babywalkers: Prevalence of use and relationship with other safety practices. Inj Prev 4: 295-298.

3. Shiva F, Ghotbi F, Yavari SF (2010) The use of baby walkers in Iranian infants. Singapore Med J 51: 645-649.

4. Garrett M, McElroy AM, Staines A (2002) Locomotor milestones and babywalkers: Cross sectional study. BMJ 324: 1494.

5. Thein MM, Lee J, Tay V, Ling SL (1997) Infant walker use, injuries, and motor development. Inj Prev 3: 63-66.
6. DiLillo D, Damashek A, Peterson L (2001) Maternal use of baby walkers with young children: Recent trends and possible alternatives. Inj Prev 7: 223-227.

7. Dogan DG, Bilici M, Yilmaz AE, Catal F, Keles N (2009) Baby walkers: A perspective from Turkey. Acta Pædiatr 98: 1656-1660.

8. Mete M, Devecioğlu E, Boran P, Yetim A, Pazar, A, et al. (2017) Baby walker use and its consequences in a group of Turkish children. J Child 17: 158-162.

9. American Academy of Pediatrics, Committee on Injury and Poison Prevention (2001) Injuries associated with infant walkers. Pediatrics 108: 790-792.

10. Peden M, World Health Organization (2018) World Report on Child Injury Prevention. Geneva, World Health Organization.

11. Sims A, Chounthirath T, Yang J, Hodges NL, Smith GA (2018) Infant walker-related injuries in the United States. Pediatrics 142: e20174332.

12. Alessa M, Humoud M, Qabandi WA (2015) Parental attitudes toward the use of baby walkers. Int $\mathrm{J}$ Health Sci (Qassim) 3: 109-113.

13. Siegel AC, Burton RV (1999) Effects of baby walkers on motor and mental development inhuman infants. J Dev Behav Pediatr 20: 355-361.

14. Chagas PS, Mancini MC, Tirado MG, Megale L, Sampaio RF (2011) Beliefs about the use of baby walkers. Rev Bras Fisioter 15: 303-309.

15. Smith GA, Bowman MJ, Luria JW, Shields BJ (1997) Babywalker-related injuries continue despite warning labels and public education. Pediatrics 100: 1 .

16. Badihian S, Adihian N, Yaghini O (2017) The effect of baby walker on child development: A systemic review. Iran J Child Neurol 11: 1-6.

17. Sertgil NK, Özen DŞ, Gökçay EG (2015) The SocialCommunication Area Developmental Screening Test for infants and young children. Çocuk Sağlığı ve Hastalıkları Dergisi 58: 87-95.

18. Kara B, Mukaddes NM, Altınkaya I, Güntepe D, Gökçay G, et al. (2014) Using the Modified Checklist for Autism in toddlers in a well-child clinic in Turkey: Adapting the screening method based on culture and setting. Autism 18: 331-338.

19. Sezgin N (2011) Two different validity study of Ankara Developmental Screening Inventory (ADSI): Criterionrelated validity and concurrent discrimination validity. Turk J Child Adolesc Ment Health 18: 185-196.

20. Burrows $P$, Griffiths $P$ (2002) Do baby walkers delay onset of walking in young children? $\mathrm{Br} \mathrm{J}$ Community Nurs 7: 581586.

21. Ruzbarsky JJ, Scher D, Dodwell E (2016) Toe walking: Causes, epidemiology, assessment, and treatment. Curr Opin Pediatr 28: 40-46.

22. Sivaramakrishan S, Seal A (2015) Fiften minute consultation: A child with toe walking. Arch Dis Child Educ Prac Ed 100: 238-241. 